\title{
Sensitivity Analysis of Buried Jointed Pipelines Subjected to Earthquake Waves
}

\author{
Alireza Boorboor, Mahmood Hosseini \\ Department of Structure, International Institute of Earthquake Engineering and Seismology, Tehran, Iran \\ Email: a.boorboor@iiees.ac.ir, Hosseini@iiees.ac.ir
}

Received 6 April 2015; accepted 22 May 2015; published 25 May 2015

Copyright (C) 2015 by authors and Scientific Research Publishing Inc.

This work is licensed under the Creative Commons Attribution International License (CC BY). http://creativecommons.org/licenses/by/4.0/

c) (i) Open Access

\begin{abstract}
In this study, a number of nonlinear time-history dynamic analyses are conducted on a part of Tehran water distribution network to investigate its functionality during transient large ground motions. The network is of 950-meter length, consisting of ductile iron pipes segments of 6-meter length. Pipes are modeled using beam elements and springs characterize the connections. Considering the time lag between support inputs, and the nonlinear soil-pipe interaction, by scaling the amplitude of the Tab as earthquake record, incremental dynamic analysis is carried out on the network in two orthogonal directions and the sensitivity of the network response is examined. Furthermore, the effects of variations in soil damping and soil spring stiffness are also studied in the network analysis. Finally the effect of changes in angle between incoming wave and pipeline is considered on a simplified network. Results show that the points other than critical ones at network intersections remain almost intact and when the angle of incidence is $\mathbf{3 0}$ degrees the stress and rotation peak.
\end{abstract}

\section{Keywords}

Jointed Buried Pipelines, Multisupport Excitation, Three Component Displacement Records, Nonlinear Soil-Pipe Interaction, Finite Element Method

\section{Introduction}

Water supply networks are one of the main components of urban infrastructures and their continuous and uninterrupted operation is of great importance in today's life. These networks are vulnerable to seismic wave propagation, and adverse consequences followed directly or indirectly from damages, affect the citizens. Since the jointed pipe network constitutes a significant part of Tehran's water supply system, investigating the network operation during the design earthquake and ensuring its functionality after the earthquake is necessary. 
For the first time in 1930, earthquake effects on water networks were considered. However, analytical and numerical studies have started since two decades ago [1]. So far seismic damage assessment on water distribution networks has been conducted by using various methods including theoretical methods such as artificial neural network [2]. Due to difficulties in describing ground-motion intensity over a region and since the link between the ground-motion intensities and lifeline performance was usually not available in closed form, Jayaram and Baker (2009) proposed a simulation-based framework for developing a small but stochastically-representative catalog of earthquake ground-motion intensity maps that could be used for lifeline risk assessment [3]. Regarding the jointed pipeline networks with brittle materials, failures have been reported due to wave propagation [4] [5]. Toprak et al. evaluated the performance of the water supply system in Denizli, Turkey. They compared the relative effects of transient ground deformations and permanent ground deformations based on maps of liquefiable soil and zones of predicted lateral ground displacements [6].

During the past earthquakes, most of the jointed pipe network failures have occurred at connections, where connection pull-out, cut and crushing (concrete pipe connections) have been reported [1]. A large number of the studies have been done on continuous pipeline networks, and because of the complexities in jointed pipe networks compared with the continuous ones, fewer studies on jointed pipe networks considering connection behavior have been made. Most of the studies on jointed pipe networks have been based on observations or estimations, and only in the past two decades, thanks to software and laboratory advances, research in this area has been expanded. Abdoun et al. (2009) conducted an experimental study on the behavior of buried continuous pipeline subjected to ground faulting [7]. Karamitros et al. (2007) presented a rigorous method to calculate the response of continuous pipes considering the axial and bending stiffness [8]. Junhee Kim et al. carried out the experimentation of a reinforced concrete segmented concrete pipeline. Accurate measures of pipeline displacements and strains were captured up to the compressive and flexural failure of the pipeline joints [9]. And recently a new method was proposed to investigate the performance of jointed buried pipelines considering the nonlinear behavior of connections [10].

This study is carried out on a part of water supply network of Tehran in which, ductile iron pipes of 6 meter length and connections of Tyton and Bolted gland types are used. By scaling the amplitude of the Tabas earthquake record, incremental dynamic analysis is carried out on the network in two orthogonal directions and the sensitivity of the network response is examined. Besides, the effect of changes in soil damping and stiffness coefficients are studied. Finally, the effect of change in the angle of incidence is studied on a simplified network, as well.

\section{Network Modeling}

In this study, a part of Tehran water distribution pipeline network is considered with an overall length of 950 meters. It is constituted of a number of bends, culverts and straight pipes. The sketch of this network including the types of connections and pipe diameters is shown in Figure 1, and Table 1 presents the pipeline lengths and the connection types in the network. It should be mentioned that, stiffness of the equivalent springs are extracted from reference [10].

\section{Soil-Pipe Interaction}

This interaction has been taken into account based on reference [11], in which the behavior of soil is modeled by bilinear springs, whose specifications depend on the pipe diameter, soil type and density, its internal friction angle, and the burial depth of pipe. Samples of curves corresponding to soil pipe interaction are shown in Figure 2 .

\section{Seismic Analysis of the Network}

\subsection{Incremental Dynamic Analysis of the Network}

Considering Tabas earthquake record and assuming the wave velocity of $200 \mathrm{~m} / \mathrm{s}$, incremental dynamic analysis of the network is performed in two directions. Earthquake scaling factor varies between 0.25 and 3 . The upper limit is considered according to: 1 ) the largest probable displacement resulting from wave propagation, which is 3 meters, and 2) the fact that the maximum displacement of Tabas record is about 1 meter. Results of these analyses are presented in the following section. 


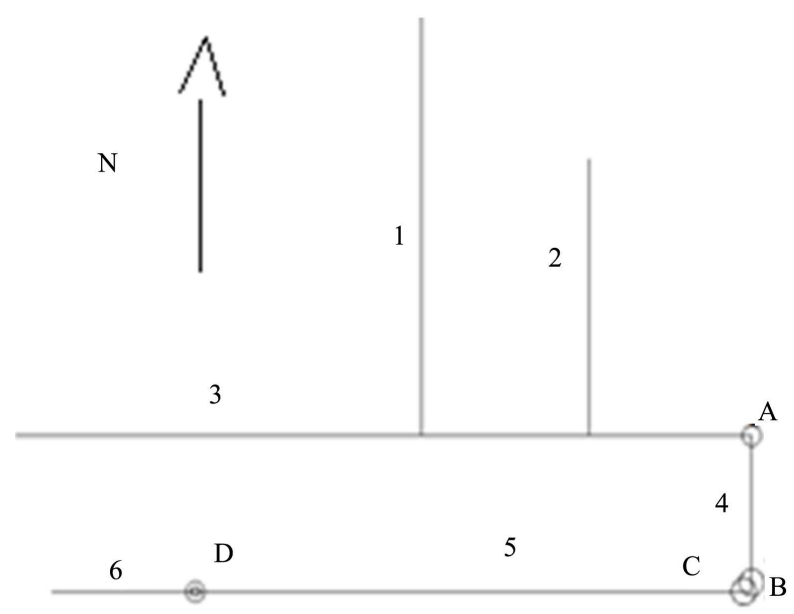

Figure 1. The sketch of the studied network.

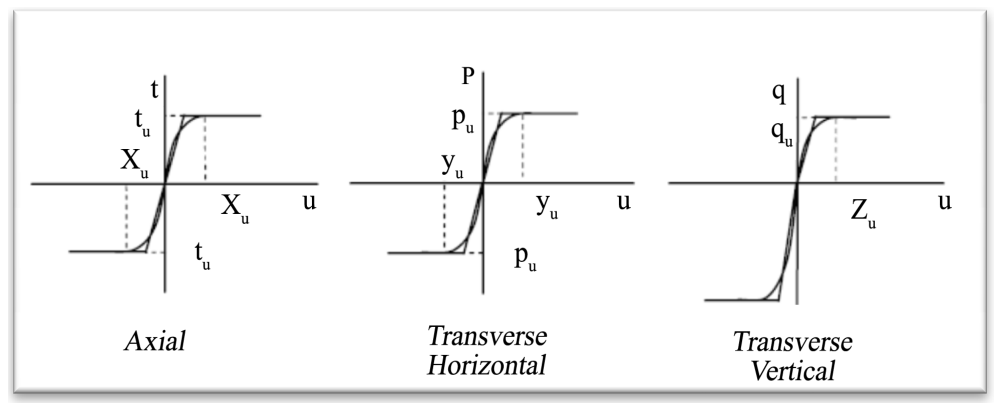

Figure 2. Bilinear behavior of soil equivalent springs.

Table 1. Length of the pipes and types of the connections in the network.

\begin{tabular}{cc}
\hline 1 & Tyton 150 pipeline $\mathrm{L}=251 \mathrm{~m}$ \\
2 & Tyton 150 pipeline $\mathrm{L}=96 \mathrm{~m}$ \\
3 & Tyton 200 pipeline $\mathrm{L}=290 \mathrm{~m}$ \\
5 & Tyton 200 pipeline $\mathrm{L}=36 \mathrm{~m}$ \\
6 & Tyton 300 pipeline $\mathrm{L}=234 \mathrm{~m}$ \\
A & Tyton 200 pipeline $\mathrm{L}=\mathbf{4} \mathrm{m}$ \\
B & Bend 200, connected to the pipeline from both ends \\
C & Bend 300, connected to the pipeline from one end \\
D & 200 culvert, connected to the pipeline from one end (mono) \\
\hline
\end{tabular}

\subsubsection{Wave Propagation in North-South Direction}

Figures 3-5 represent the maximum stress in the network, the maximum rotation along Tyton 150 pipeline, and the maximum rotation of the critical point for a seismic scale increase respectively.

\subsubsection{Wave Propagation in East-West Direction}

Figures 6-9 represent the maximum stress in the network, the maximum rotation along Tyton 200, 300 pipelines and the maximum rotation of the critical point, for a seismic scale increase respectively. 


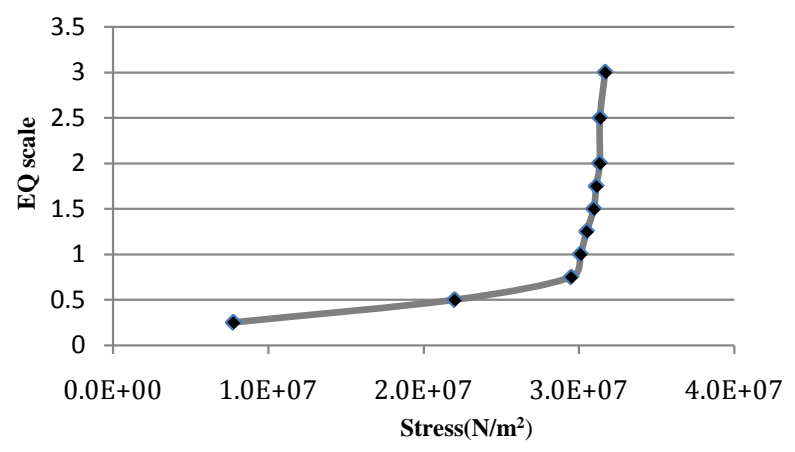

Figure 3. Stress changes for increasing earthquake intensity in $\mathrm{N}-\mathrm{S}$ direction.

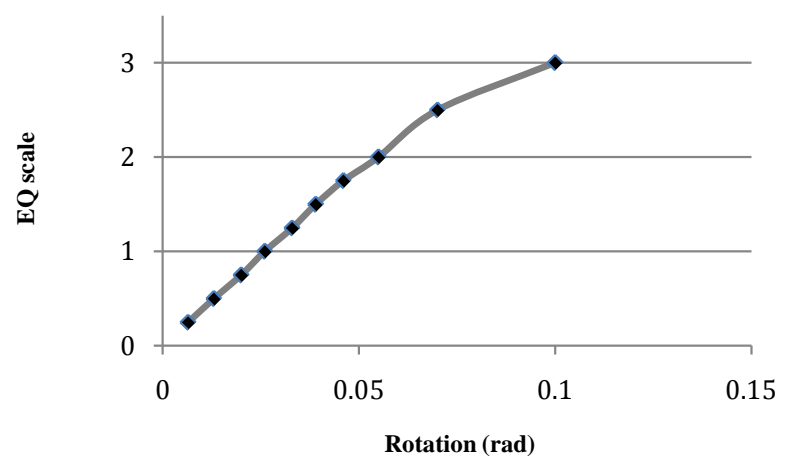

Figure 4. Rotation changes along Tyton 150 pipeline for increasing earthquake intensity in N-S direction.

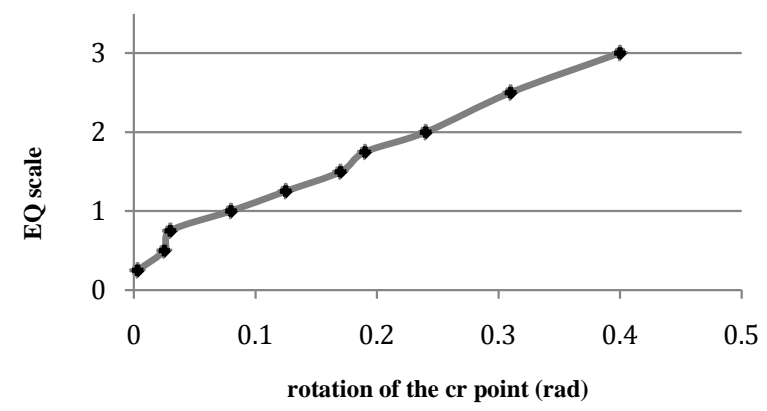

Figure 5. Rotation changes in critical point for increasing earthquake intensity in $\mathrm{N}-\mathrm{S}$ direction.

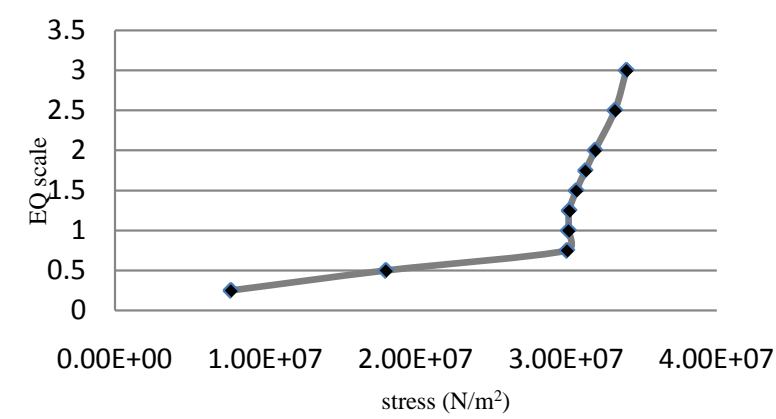

Figure 6. Stress changes for increasing earthquake intensity in $\mathrm{E}-\mathrm{W}$ direction. 


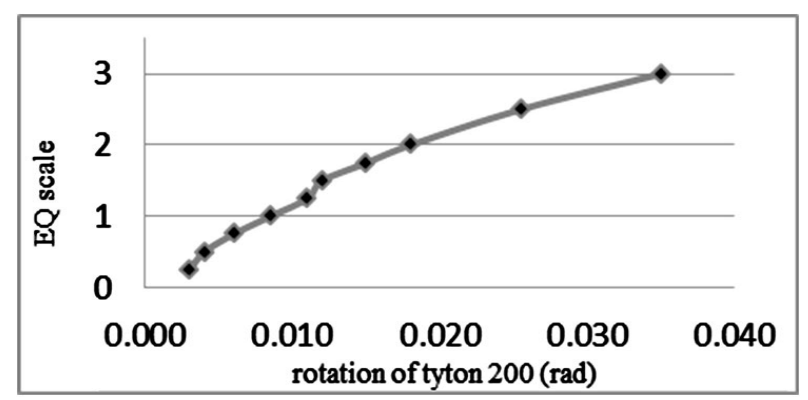

Figure 7. Rotation changes in Tyton 200 pipeline for increasing earthquake intensity in E-W direction.

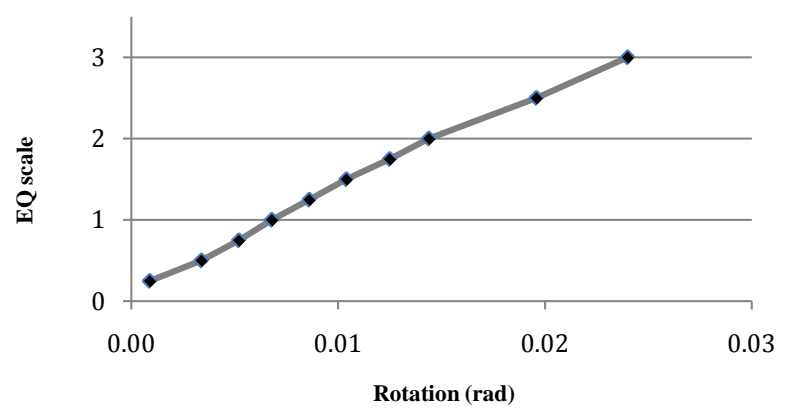

Figure 8. Rotation changes in Tyton 300 pipeline for increasing earthquake intensity in E-W direction.

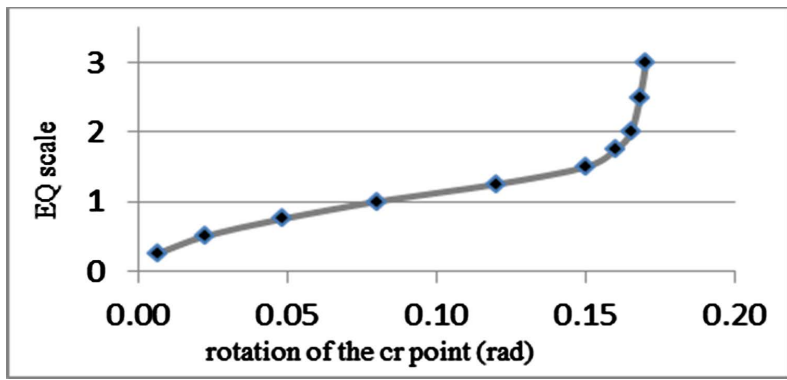

Figure 9. Rotation changes in critical point for increasing earthquake intensity in E-W direction.

In Figure 3 and Figure 6, stress after the yielding point becomes completely non-linear and with increasing displacement, stress level increases at a lower rate. While as can be seen in Figure 4, Figure 5, Figure 7, and Figure 8 the values of rotations increase almost linearly with respect to the displacement. With increasing the relative displacements, stresses increase slightly after reaching the yielding point. Considering Figure 3 in the IDA analysis, it can be said that in the elastic range, with increasing displacement scale from 0.25 to 0.75 , the stress increases by 3.8 times. While within the plastic range, with increasing the scale from 1 to 3 , the stress level increases only 5\%. In contrast, rotations increase almost linearly and do not tend to a certain value.

According to the performed analyses, it may be suggested that in jointed pipe networks under the effect of transient ground waves, stress level or rotation along the lines (except in very large displacements) is negligible, and an effective damage is probable only at the intersection points or where the lines' directions vary i.e. at the bends.

\subsection{Investigating the Effects of Damping}

Soil damping in previous analyses has been assumed to be smaller than the real value $(0.05)$, which leads to conservative response values. A larger damping value, however, is expected to reduce the effective displacement 
imposed to the network. To examine the effects of damping, Tabas earthquake record with a scale factor of 1.5 is applied to the network in N-S direction with a velocity of $200 \mathrm{~m} / \mathrm{s}$. The reason of using this record is to make sure that the system becomes adequately nonlinear to provide a basis for the comparison of the results. The analyses are performed using this record and considering the damping coefficients of $0.2,0.3$ and 0.4 in the mechanical properties of soil equivalent springs. Table 2 shows the maximum stress and rotation in the network and the maximum rotation in Tyton 150 pipeline connections for changes in various damping coefficients.

As can be observed from Table 2, with increasing the damping coefficient of the equivalent springs (surrounding soil), stress levels are reduced. With a $10 \%$ increase in damping coefficient, stress decreases by $4.5 \%$ in the elastic range. Nevertheless, the effects of damping coefficient changes are lower in the plastic range, and by a $10 \%$ increase in damping coefficient, stress decreases by $1 \%$.

It is worth mentioning that the rotations are recorded at the connections, while the maximum stress occurs at a point outside of the connection and there is no direct relationship between the rotations and the maximum stress values.

\subsection{Analysis with San Fernando Earthquake Record}

In a time-history analysis not only PGD but also the frequency content of record can affect the response of the system. Since by now whole of the analysis is carried out using the Tabas earthquake record, to investigate the behavior of the network under an earthquake record with a different frequency content, the network is subjected to the San Fernando earthquake record in N-S and E-W directions. Figure 10 shows the three component displacement record of the San Fernando earthquake.

\subsubsection{Wave Propagation in North-South Direction}

The general trends of stress and rotation in the network are similar to those of Tabas earthquake record. Table 3 shows the maximum stress and rotation values at the critical point and the maximum rotation along Tyton 150 pipeline.

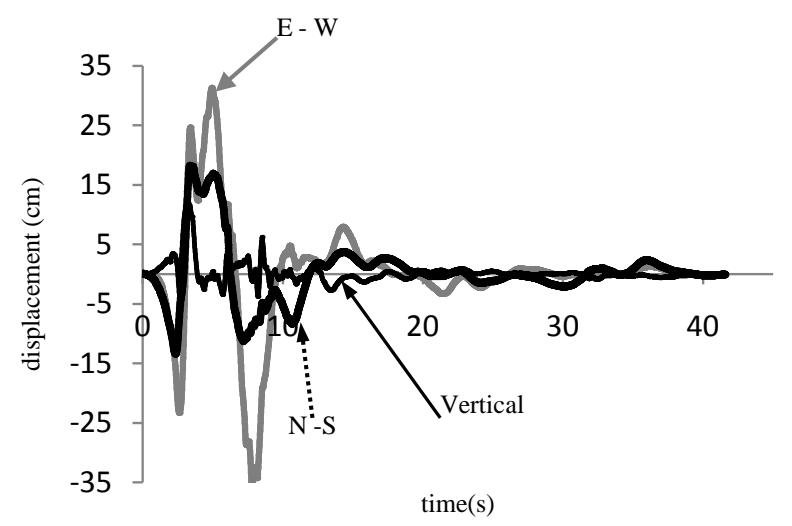

Figure 10. Three component displacement record of San Fernando earthquake.

Table 2. Stress and rotation variations for changes in damping.

\begin{tabular}{cccc}
\hline Damping & Stress & Cr point (rad) & \multicolumn{2}{c}{ Tyton150 } \\
\hline$\%$ & $\left(\mathrm{~N} / \mathrm{m}^{2}\right)$ & 0.11 & 0.04 \\
\hline 20 & $3.03 \mathrm{e}+08$ & 0.09 & 0.038 \\
30 & $2.98 \mathrm{e}+08$ & 0.06 & 0.038 \\
40 & $2.85 \mathrm{e}+08$ & & 0.038 \\
\hline
\end{tabular}

Table 3. Analysis results with San Fernando record along N-S direction.

\begin{tabular}{ccc}
\hline Cr point (rad) & Tyton $150(\mathrm{rad})$ & Stress $\left(\mathrm{N} / \mathrm{m}^{2}\right)$ \\
\hline 0.018 & $7.30 \mathrm{e}-03$ & $1.60 \mathrm{E}+07$ \\
\hline
\end{tabular}




\subsubsection{Wave Propagation in East-West Direction}

In E-W direction, the general trends of stress and rotation in the network are similar to those of Tabas earthquake record as well. In both directions the behavior of the network and the overall stress contours are almost the same, so one may conclude that the network response does not highly depend on the frequency content of earthquake record. Table 4 shows the maximum stress and rotation in the network, along Tyton 200 and 300 pipelines and at the intersection point of Tyton 150 and 200 pipelines and the bends.

\subsubsection{Effects of the Stiffness of the Soil around the Pipe}

Velocity of the transient wave is dependent upon the alluvial soil and independent of the back-fill soil around the pipe. To evaluate the effect of the stiffness of the back-fill soil, the stiffness of equivalent springs, with no change in the ultimate strength as well as wave velocity, is reduced by $15 \%$ and $30 \%$, and the wave along NorthSouth direction is applied to the network. Table 5 shows the maximum stress values and their corresponding rotations.

As it is indicated in Table 5, soil stiffness has a very little effect on the rotations in the connection, and with a $15 \%$ reduction in the stiffness of the surrounding soil, the stress decreases by $6 \%$ in elastic range.

\subsection{Angle of Incidence Effect on the Network Seismic Behavior}

To evaluate the effect of angle of incidence, for convenience, a simplified network, as illustrated in Figure 11, is

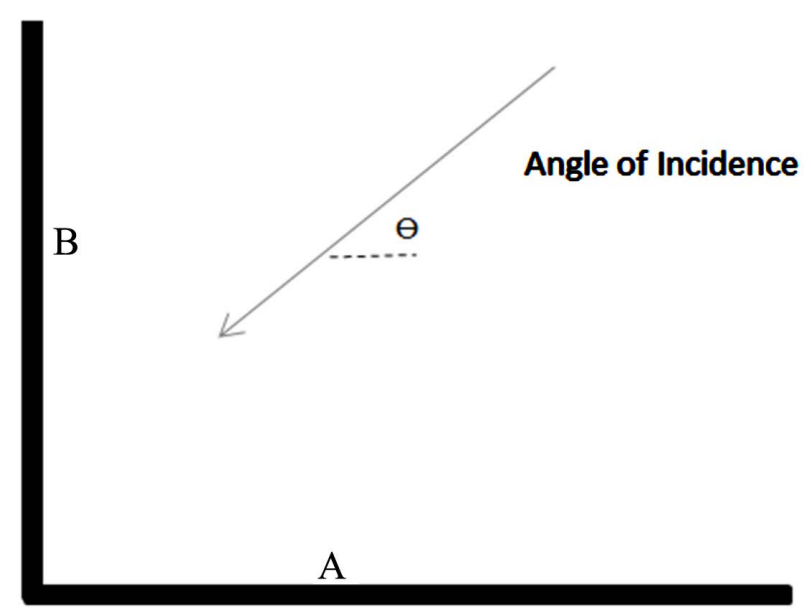

Figure 11. Sketch of the studied network.

Table 4. Analysis results with San Fernando record in E-W direction.

$\begin{array}{cc}\text { Stress }\left(\mathrm{N} / \mathrm{m}^{2}\right) & 1.9 \mathrm{e} 8 \\ \text { Tyton } 200(\mathrm{rad}) & 0.05 \\ \text { Tyton } 300(\mathrm{rad}) & 0.02 \\ \text { Tyton 150-intersection point (rad) } & 0.03 \\ \text { Bend 200 (rad) } & 0.017 \\ \text { Bend 300 (rad) } & 0.005\end{array}$

Table 5. Stress and rotation variations for changes in the stiffness of the soil around the pipe.

\begin{tabular}{cccc}
\hline Stiffness mitigation (\%) & Stress $\left(\mathrm{N} / \mathrm{m}^{2}\right)$ & Tyton $150(\mathrm{rad})$ & Cr point (rad) \\
\hline 15 & $1.6 \mathrm{e} 8$ & $7 \mathrm{e}-3$ & 0.018 \\
30 & $1.5 \mathrm{e} 8$ & $6.8 \mathrm{e}-3$ & .0170 \\
\hline
\end{tabular}


considered with three different diameters of 200,500 and $1000 \mathrm{~mm}$. ( $\theta$ is the angle between the wave direction and A branch).

Figures 12-14 show the maximum stress and the rotation for the network of diameter 200. Critical point is at the intersection of the two branches and as is shown, it can be concluded that by a change in the angle from 0 to 30 degrees the values of rotation and stress increases, however, these numbers minimize at 45 degrees.

In the same way, the networks of 500 and $1000 \mathrm{~mm}$ are examined and the results, similarly, show that with an increase in the angle of incidence from 0 to 30 degrees the values of rotation and stress rise and from 30 to 45 the relation between the angle and the quantities of stress and rotation is reverse.

Figures 15-20 show the rotation in branch(s) A and B and the maximum stress in the networks of 500 and $1000 \mathrm{~mm}$, respectively.

\section{Conclusions}

1) As expected, by increasing the velocity and consequently decreasing the phase difference, damages are reduced. By increasing the velocity from 150 to $200 \mathrm{~m} / \mathrm{s}$, stress level in plastic range decreases by $2 \%$, and by

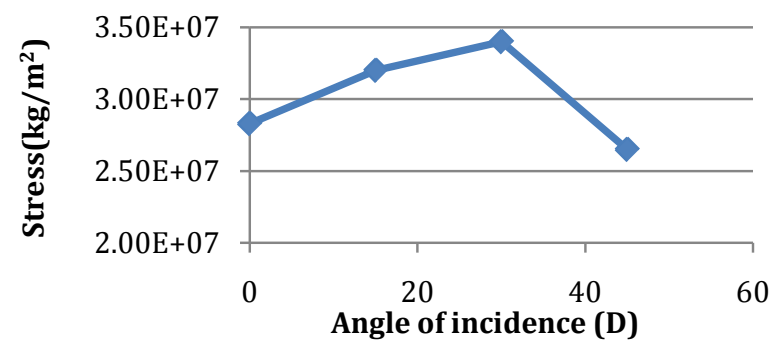

Figure 12. Angle of incidence and corresponding maximum stress in the network of $200 \mathrm{~mm}$.

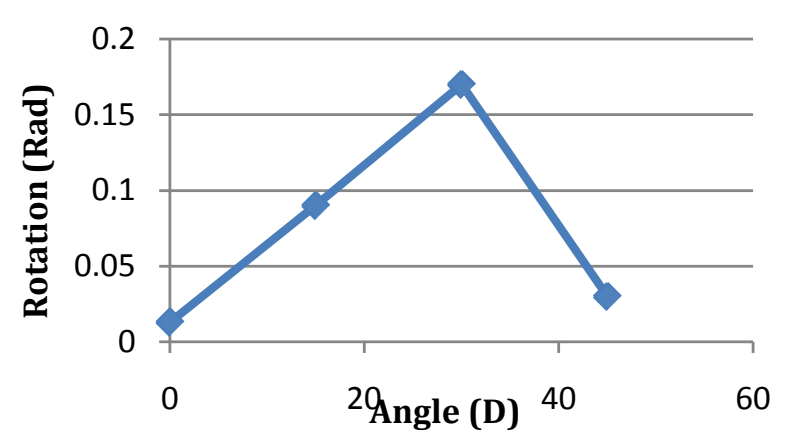

Figure 13. Angle of incidence and corresponding maximum rotation along the A pipeline in the network of $200 \mathrm{~mm}$.

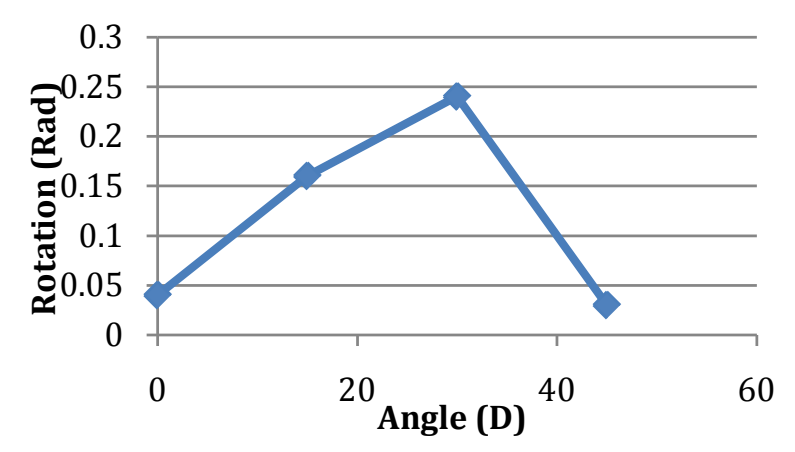

Figure 14. Angle of incidence and corresponding maximum rotation along the B pipeline in the network of $200 \mathrm{~mm}$. 


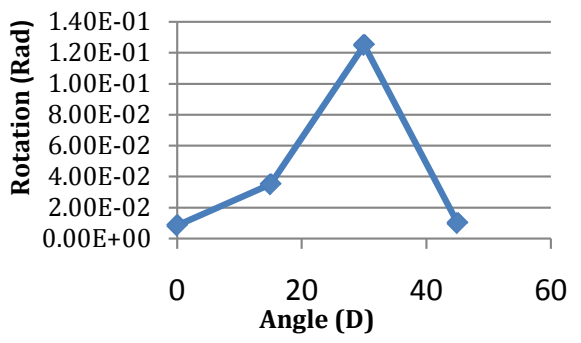

Figure 15. Angle of incidence and corresponding maximum rotation along the A pipeline in the network of $500 \mathrm{~mm}$.

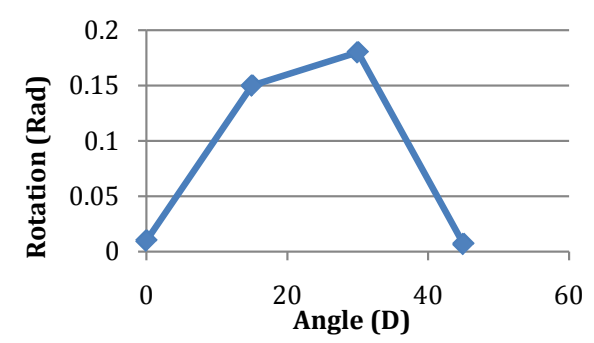

Figure 16. Angle of incidence and corresponding maximum rotation along the B pipeline in the network of $500 \mathrm{~mm}$.

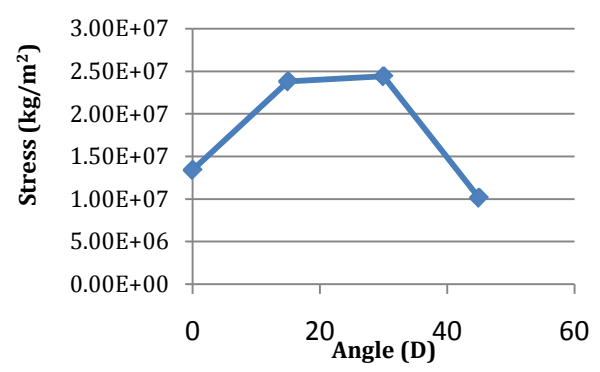

Figure 17. Angle of incidence and corresponding maximum stress in the network of $500 \mathrm{~mm}$.

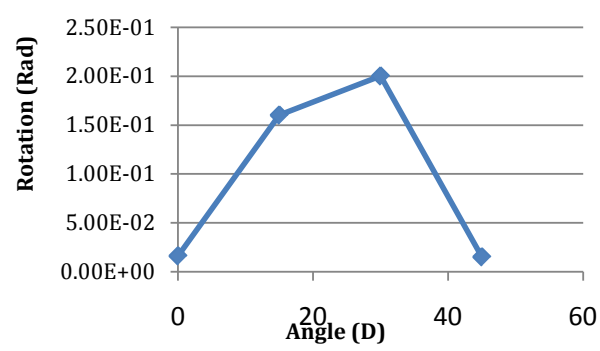

Figure 18. Angle of incidence and corresponding maximum rotation along the A pipeline in the network of $1000 \mathrm{~mm}$.

creasing the velocity from 200 to $300 \mathrm{~m} / \mathrm{s}$, stress level is decreased by $12 \%$ within the elastic range and the plastic limit.

2) By increasing the relative displacement, stresses increase slightly after reaching the yielding point. Considering the stress diagram in North-South direction in IDA analysis, it can be said that within the elastic range, by increasing displacement scale from 0.25 to 0.75 , the stress increases by 3.8 times. While within the plastic range, by increasing the scale from 1 to 3 , the stress level increases by only $5 \%$. However, rotations increase almost 


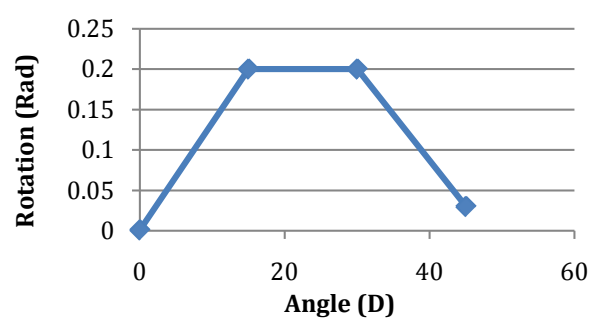

Figure 19. Angle of incidence and corresponding maximum rotation along the $B$ pipeline in the network of $1000 \mathrm{~mm}$.

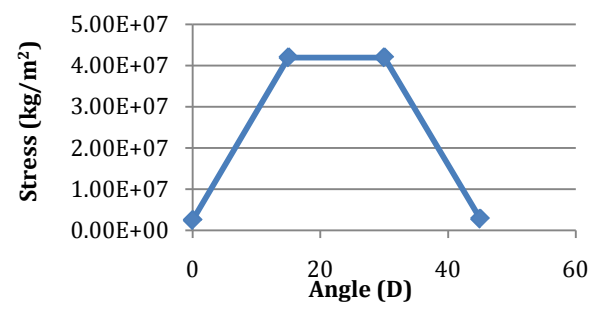

Figure 20. Angle of incidence and corresponding maximum stress in the network of $1000 \mathrm{~mm}$.

linearly and do not tend to a certain value.

3) Changing the soil or equivalent springs' stiffness in a reasonable range does not cause a significant difference in the results. However, in general, by decreasing the stiffness of the soil springs, stress and rotation levels are reduced because the spring (soil)-pipe system is typically arranged in a series. By a $15 \%$ reduction in the surrounding springs' stiffness, stress level decreases by $6 \%$ in the elastic range.

4) By increasing the damping of the equivalent springs (surrounding soil), stress levels are reduced. With a $10 \%$ increase in damping, stress level decreases by $4.5 \%$ in the elastic range. The effects of damping changes are lower in the plastic range and by a $10 \%$ increase in the damping coefficient, the stress value decreases by $1 \%$.

5) Regarding the results of the effect of change in the angle between incoming wave direction and pipeline, it can be concluded that the amounts of rotation and stress peak at the angle of 30 degrees and these figures are almost the same for 0 and 45 degrees. In summary, by an increase in the angle of incidence from 0 to 30 amounts of rotation and stress increase, and between 30 and 45 the measures decrease to the level it was at 0 degree.

\section{References}

[1] O’Rourke, M.J. and Liu, X. (1999) Response of Buried Pipelines Subjected to Earthquake Effect. MCEER Report.

[2] Takada, S., Hassani, N. and Rasti, R. (2003) Artificial Neural Network (ANN) Modeling for Earthquake Damage Detection in Water Distribution System. Proceedings of the 2003 Pacific Conference on Earthquake Engineering [Electronic Resource], 9 p.

[3] Jayaram, N. and Baker, J.W. (2009) Efficient Sampling and Data Reduction Techniques for Probabilistic Seismic Lifeline Risk Assessment. Earthquake Engineering and Structural Dynamics, 39, 1109-1131.

[4] Toprak, S. and Taskin, F. (2007) Estimation of Earthquake Damage to Buried Pipelines Caused by Ground Shaking. Natural Hazards, 40, 1-24. http://dx.doi.org/10.1007/s11069-006-0002-1

[5] Shi, P., O’Rourke, T.D., Wang, Y. and Fan, K. (2008) Seismic Response of Buried Pipelines to Surface Wave Propagation Effect. Proceeding of the 14th World Conference on Earthquake Engineering, Beijing, 12-17 October 2008.

[6] Toprak, S., Taskin, F. and Koc, A.C. (2009) Prediction of Earthquake Damage to Urban Water Distribution Systems: A Case Study for Denizli, Turkey. Bulletin of Engineering Geology and the Environment, 68, 499-510. http://dx.doi.org/10.1007/s10064-009-0230-1

[7] Abdoun, T.H., Ha, D., O’Rourke, M.J., Symans, M.D., O’Rourke, T.D., Palmer, M.C. and Stewart, H.E. (2009) Factors Influencing the Behavior of Buried Pipelines Subjected to Earthquake Faulting. Journal of Soil Dynamics and Earthquake Engineering, 29, 415-427. http://dx.doi.org/10.1016/j.soildyn.2008.04.006 
[8] Karamitros, D.K., Bouckovalas, G.D. and Kouretzis, G.P. (2007) Stress Analysis of Buried Pipelines at Strike Slip Fault Crossing. Soil Dynamics and Earthquake Engineering, 27, 200-211. http://dx.doi.org/10.1016/j.soildyn.2006.08.001

[9] Kim, J., et al. (2010) Behavior of Full Scale Concrete Segmented Pipelines under Permanent Ground Displacements. Proceedings of SPIE, Health Monitoring of Structural and Biological Systems, 7650, 76500U-1-76500U-11. http://dx.doi.org/10.1117/12.847735

[10] Boorboor, A. and Hosseini, M. (2015) Evaluation of Water Distribution Jointed Pipe Networks under Transient Ground Motions. Open Journal of Civil Engineering, Previously Accepted.

[11] American Society of Civil Engineers (ASCE) (1984) Guidelines for the Seismic Design of Oil and Gas Pipeline Systems. Committee on Gas and Liquid Fuel Lifeline, ASCE, Reston. 